\title{
PHYSICAL FITNESS PERFORMANCE, PLAYING POSITION AND COMPETITIVE LEVEL ATTAINED BY ELITE JUNIOR SOCCER PLAYERS: A 12-YEAR STUDY
}

\author{
Asier Los Arcos ${ }^{1}$ and Asier Gonzalez-Artetxe ${ }^{2}$ \\ ${ }^{1}$ Society, Sports and Physical Exercise Research Group (GIKAFIT), \\ Department of Physical Education and Sport, University of the Basque Country UPV/EHU Spain \\ ${ }^{2}$ Department of Physical Education and Sport, \\ University of the Basque Country UPV/EHU, Spain
}

Original scientific paper

DOI: $10.26582 / \mathrm{k} .53 .1 .6$

\begin{abstract}
:
The aim of this study was to look into the alleged impact of the physical fitness performance of elite junior soccer players on the professional career according to playing position. Physical tests (sprint test, countermovement jump [CMJ], and maximal aerobic speed [MAS]) performed by 165 players enrolled in the junior team of a Spanish 1st Division club (1998-2010) were evaluated. Players were classified as those who were promoted to the reserve team (Reserve Team) and those who were not (non-Reserve Team), and as those who were promoted to the Spanish $1^{\text {st }} / 2^{\text {nd }}$ Divisions (PFL) and those who were not (NPFL) until the 2020-2021 season. Overall, no significant differences ( $p>.05)$ were found between the Reserve Team and non-Reserve Team or between the PFL and NPFL players in neuromuscular performance. Aerobic fitness was greater $(\mathrm{p}<.05 ; \mathrm{ES}=.79 \pm .60$, moderate; mean difference $=3.0 \%)$ for the Reserve Team lateral midfielders in comparison to the same position players for the non-Reserve Team. The results suggest that the impact of physical fitness on the promotion of elite junior soccer players is limited.
\end{abstract}

Key words: team sport, talent identification, testing, aerobic fitness, acceleration, jumping ability

\section{Introduction}

The main aim of soccer training is the optimization of the specific motor competence of soccer, which derives from the interaction between various dimensions (i.e. physical-physiological, decisionmaking, cognitive, and emotional) (Huijgen, Elferink-Gemser, Lemmink, \& Visscher, 2014) of the entire person (i.e. the soccer player). As numerous factors determine this type of competence, the processes of talent identification and development are complex (Reilly, Williams, Nevill, \& Franks, 2000; Zuber, Zibung, \& Conzelmann, 2016). Although decision-making ability is presumed to be particularly important in soccer at the elite level (Gonçalves, Rama, \& Figueiredo, 2012; Roca, Williams, \& Ford, 2012) and several studies have found that this dimension does discriminate between expert and less skilled players (Roca, et al., 2012; Vaeyens, Lenoir, Williams, \& Philippaerts, 2007), the physical-physiological dimension also seems to be a relevant factor (Castillo, Los Arcos, \& Martínez-Santos, 2018; Coelho E Silva, et al., 2010; Gil, et al., 2014; Lago-Peñas, Rey, Casáis,
\& Gómez-López, 2014; le Gall, Carling, Williams, \& Reilly, 2010; Martinez-Santos, Castillo, \& Los Arcos, 2016) that should be assessed. Thus, in addition to assisting the creation and individual tailoring of physical training and appropriate recording and monitoring (Craig \& Swinton, 2020), soccer academies continually collect data on physical fitness performance of their players (Craig \& Swinton, 2020; Gonaus, Birklbauer, Lindinger, Stöggl, \& Müller, 2019; Los Arcos, Martínez-Santos, \& Castillo, 2020; Los Arcos \& Martins, 2018) to assess whether accurate predictions can be made about the promotion level based on that dimension of soccer players.

Several studies have compared levels of physical fitness performance between young players who were promoted and young soccer players $(<$ U17) who were not promoted in soccer academies (Carling, le Gall, \& Malina, 2012; Coelho E Silva, et al., 2010; Craig \& Swinton, 2020; Gil, et al., 2014). However, few studies have examined whether physical fitness performance at the junior and adult age category determines professional 
careers of soccer players from elite soccer schools (Castillo, et al., 2018, 2019; Martinez-Santos, et al., 2016), that is, when the relative age effect (RAE) becomes reduced. Since the selection of players to compete at a high level is of great importance in elite soccer academies and the transition from the academy to the professional level (Mills, Butt, Maynard, \& Harwood, 2012) is a critical stage in the progress of every player's career (Vaeyens, Coutts, \& Philippaerts, 2005), several studies have assessed the importance of the anthropometric profile (Vega, Gonzalez-Artetxe, Aguinaco, \& Los Arcos, 2020) and physical fitness performance in two elite Spanish reserve teams (Castillo, et al., 2018; Los Arcos, et al., 2020; Martinez-Santos, et al., 2016). Martinez-Santos et al. (2016) and Castillo et al. (2018) found that neuromuscular performance, except for central defenders, and endurance performance were not relevant physical parameters for being promoted from an elite reserve team to the top level of soccer in Spain. These results suggested that the players in an elite Spanish reserve team not only possessed right neuromuscular and endurance profiles required for Spanish high-level soccer players (Castillo, et al., 2018; Martinez-Santos, et al., 2016), but also that playing position should be considered in this type of analysis.

With respect to the previous step to the elite reserve team, few studies have assessed the relevance of physical fitness performance in junior soccer players. Similarly to the studies carried out with elite reserve team players (Castillo, et al., 2018; Martinez-Santos, et al., 2016), no differences were found in physical characteristics (i.e. Abalakov jump, $10 \mathrm{~m}$ and $30 \mathrm{~m}$ sprints and flexibility) between the U18 age category players promoted to an elite soccer club from the Spanish "La Liga" and those not promoted (Castillo, et al., 2019). Although it seems that physical fitness performance does not determine the promotion from the junior and reserve teams to the elite soccer team in a soccer school, little is still known about this issue and more studies are needed to help researchers and practitioners within soccer academies adequately assess the relevance of junior players' physical fitness performance to their success in the sport (i.e. promotion to top-level soccer teams) (Craig \& Swinton, 2020). Thus, the main purpose of this study was to research the alleged impact of physical fitness performance of Spanish elite junior soccer players on their professional career according to playing positions. Our hypothesis was that better physical fitness performance of junior soccer players in an elite soccer academy was not advantageous for their promotion to the reserve team of the club and to high-level soccer.

\section{Methods}

\section{Participants}

One hundred sixty-five players (age $=18.5 \pm 0.6$ years), belonging to the junior team of a Spanish elite soccer academy participated in the study. They competed in the junior Spanish $1^{\text {st }}$ Division during the period 1998-1999 to 2009-2010. We classified the participating junior players into those who were promoted to the reserve team (Reserve Team) of the same club and those who were not (non-Reserve Team). Moreover, after reviewing the sports careers of all the players included in our sample up to the end of the 2016-2017 season and identifying their highest competitive level, we assigned them to one of the two following groups (Martinez-Santos, et al., 2016; Vega, et al., 2020): 1) Professional Football League (PFL): players who succeeded in signing a contract and played at least one match as a fulltime professional with the Spanish $1^{\text {st }}$ or $2^{\text {nd }}$ Division; 2) and semi-professional (non-Professional FL - NPFL): players who never signed a contract with a Spanish $1^{\text {st }}$ or $2^{\text {nd }}$ Division club. In addition to the highest performance level attained, the playing positions of the 165 players we recorded based on the criteria of their trainer (Castillo, et al., 2018; Los Arcos \& Martins, 2018; Martinez-Santos, et al., 2016): goalkeepers $(\mathrm{n}=13)$, lateral defenders $(\mathrm{n}$ $=31)$, central defenders $(\mathrm{n}=30)$, lateral midfielders $(\mathrm{n}=31)$, central midfielders $(\mathrm{n}=27)$, and forwards $(\mathrm{n}=33)$.

\section{Procedure}

This research was carried out in a Spanish club that has run its own elite academy since 1982. We collected the scores from the physical conditioning tests performed by the elite junior soccer players of the club during the period 1998-1999 to 20092010, comprising 12 seasons in total. We calculated the percentage of players who: a) played in the junior team and were later promoted to the club's reserve team; and b) played in the junior team and later reached professional competitive level $\left(\mathrm{PFL}=\right.$ Spanish $1^{\text {st }}$ and $2^{\text {nd }}$ Division $)$. Moreover, we compared performance using the same physical fitness parameters between junior players who were or were not promoted to the reserve team and between those who did or did not compete in the PFL (Spanish $1^{\text {st }}$ and $2^{\text {nd }}$ Divisions), according to their playing positions.

According to the protocols established by the club, players had to complete the same battery of physical tests, including CMJ, linear 5 and $15 \mathrm{~m}$ sprints and the Université de Montréal Track Test (UM-TT), four times during the season (AugustDecember-February/March-May/June). Before the 
testing sessions, the participants were instructed to refrain from strenuous exercise for at least $48 \mathrm{~h}$ in advance and to consume their normal pretraining diet. They were already familiar with the exercises because the same battery of physical tests was used for all teams (i.e., U13, U14, U15, U16, U17, and U19) in the soccer school. The tests were carried out in the same sport facilities. Before each testing session, the same standardized warm-up was performed, consisting of five minutes of self-paced low-intensity running, mobility exercises, strides, and acceleration drills. Mean values of all tests performed by each player during the season were recorded for analysis.

\section{Physical fitness assessment}

Sprint test. The sprint test consisted of three maximal sprints over $15 \mathrm{~m}$ with a $120 \mathrm{~s}$ rest period between each trial, giving enough time to walk back to the start line and wait for another turn (MartinezSantos, et al., 2016). The players, standing $0.5 \mathrm{~m}$ behind the starting point, set off when they felt ready. The score was measured with an accuracy of $\pm 0.001 \mathrm{~s}$ by means of a system of photocell gates (Racetime 2, Microgate, Italy) placed $0.4 \mathrm{~m}$ above the ground. The timer, automatically activated as the players crossed the first gate at the $0.0 \mathrm{~m}$ mark, recorded split times at $5 \mathrm{~m}$ and $15 \mathrm{~m}$. The best sprint time (i.e., $5 \mathrm{~m}$ and $15 \mathrm{~m}$ ) in each test session was subsequently used to calculate the mean for the season. The sprint test provided high values of reliability for measuring the sprinting performance on short distance in soccer players (Altmann, Ringhof, Neumann, Woll, \& Rumpf, 2019; Los Arcos, Mendiguchia, \& Yanci, 2017).

Jumping tests (CMJ and CMJA). Players were asked to perform a maximal countermovement vertical jump (CMJ) on a jumping mat (Newtest OY, Oulu, Finland), with their hands on their hips. They started the jump from an extended leg position, going down to a $90^{\circ}$ knee flexion immediately followed by a subsequent concentric action for maximal height and trying to land in a position as similar as possible to that at the take-off. Jump height was calculated from the flight time. Three attempts, interspersed with an approximately 20 -second rest between jumps, were recorded. The CMJA was similar to the CMJ, but in this case, an arm swing was allowed. As with the CMJ, three attempts, interspersed with an approximately 20 -second rest between jumps, were executed. The best jump (i.e. CMJ and CMJA) in each test session was subsequently used to calculate the mean for the season. Both tests provided high values of reliability for tests measuring jumping performance in soccer players (Los Arcos, et al., 2017; Rodríguez-Rosell, Mora-Custodio, Franco-Márquez, Yañez-García, \& González-Badillo, 2017).
Continuous maximal multistage running field test. The Université de Montréal Track Test (UM-TT) (Léger \& Boucher, 1980) was used to determine maximal aerobic speed (MAS). The initial speed of the multistage test was set at 6.00 $\mathrm{km} \cdot \mathrm{h}^{-1}$; thereafter, it increased by $1.20 \mathrm{~km} \cdot \mathrm{h}^{-1}$ in stages of a two-minute duration (Léger \& Boucher, 1980). Players ran, guided by cones located at specific sites on the field, following instructions aided by whistles. The test was stopped when the subject was either at least nine meters behind the appropriate cone at the sound signal, or felt that he could not complete the stage (Léger \& Boucher, 1980; Los Arcos, et al., 2019). The speed at the last completed stage measured with the UM-TT was taken as the MAS in $\mathrm{km} \cdot \mathrm{h}^{-1}$ (Léger \& Boucher, 1980). The UM-TT is a valid and reliable test to estimate $\mathrm{VO} 2$ max of trained young males (Kuipers, Verstappen, Keizer, Geurten, \& van Kranenburg, 1985; Léger \& Boucher, 1980).

\section{Statistical analysis}

Results are presented as mean \pm standard deviation (SD). Variables were normally distributed and satisfied the equality of variances according to the Kolmogorov-Smirnov test and Levene test, respectively. Thus, the Student $t$-test for independent samples was used to compare physical fitness performance levels between the non-Reserve Team and Reserve Team players and between the NPFL and PFL players by playing positions. In addition, practical differences were assessed using Cohen's d effect size (Cohen, 1988) and calculated using the modified statistical Excel spreadsheet provided by Hopkins (2007). Effect sizes (ES) between $<0.2$, $0.2-0.6,0.6-1.2,1.2-2.0$, and 2.0-4.0 were considered trivial, small, moderate, large, and very large, respectively (Hopkins, Marshall, Batterham, \& Hanin, 2009).

\section{Results}

\section{Promotion success}

Out of the total number of junior players $34 \%$, $12 \%$, and $4 \%$ were promoted to the reserve team, the Spanish $1^{\text {st }}$ Division, and the Spanish $2^{\text {nd }}$ Division, respectively. Out of the players who were promoted from the junior to the reserve team, $7 \%, 15 \%, 19 \%$, $20 \%, 17 \%$, and $22 \%$ were goalkeepers, central defenders, lateral defenders, central midfielders, lateral midfielders, and forwards, respectively.

\section{Promotion and physical fitness performance}

Overall, no significant differences ( $p>05$ ) were found between the Reserve Team and non-Reserve Team or between the PFL and NPFL players in neuromuscular performance for any of the playing positions (Tables 1 and 2). 
Table 1. Differences in sprint performance (s) between those who were not promoted to the Reserve Team (non-Reserve Team) and those who were (Reserve Team players), and between those who were not promoted to the first or second division (non-Professional FL players) and those who were (Professional FL players), by playing positions

\begin{tabular}{|c|c|c|c|c|c|c|}
\hline & & & & Difference in means (\%) & $p$ & Effect size \\
\hline \multirow{6}{*}{ Gs } & & non-Reserve Team & Reserve Team & & & \\
\hline & $5 m$ & $.98 \pm .03$ & $.97 \pm .02$ & -.1 & .89 & $-.03 ; \pm 1.05$ \\
\hline & $15 \mathrm{~m}$ & $2.33 \pm .05$ & $2.37 \pm .05$ & 1.9 & .26 & $.76 ; \pm 1.35$ \\
\hline & & non-Professional FL & Professional FL & & & \\
\hline & $5 m$ & $.98 \pm .03$ & $.97 \pm .02$ & -.1 & .89 & $-.03 ; \pm 1.05$ \\
\hline & $15 \mathrm{~m}$ & $2.33 \pm .05$ & $2.37 \pm .05$ & 1.9 & .26 & $.76 ; \pm 1.35$ \\
\hline \multirow{6}{*}{ LDs } & & non-Reserve Team & Reserve Team & & & \\
\hline & $5 m$ & $.99 \pm .05$ & $.96 \pm .03$ & -2.6 & .11 & $-.54 ; \pm .49$ \\
\hline & $15 \mathrm{~m}$ & $2.34 \pm .07$ & $2.29 \pm .06$ & -1.8 & .12 & $-.58 ; \pm .56$ \\
\hline & & non-Professional FL & Professional FL & & \multirow{3}{*}{$\begin{array}{l}.18 \\
.30\end{array}$} & \\
\hline & $5 m$ & $.99 \pm .04$ & $.96 \pm .04$ & -2.8 & & $-.64 ; \pm .80$ \\
\hline & $15 \mathrm{~m}$ & $2.33 \pm .07$ & $2.30 \pm .07$ & -1.6 & & $-.54 ; \pm 1.00$ \\
\hline \multirow{6}{*}{ CDs } & & non-Reserve Team & Reserve Team & & & \\
\hline & $5 m$ & $.97 \pm .04$ & $.95 \pm .02$ & -2.4 & .19 & $-.54 ; \pm .42$ \\
\hline & $15 \mathrm{~m}$ & $2.34 \pm .07$ & $2.30 \pm .05$ & -1.8 & .11 & $-.61 ; \pm .58$ \\
\hline & & non-Professional FL & Professional FL & & & \\
\hline & $5 m$ & $.97 \pm .04$ & $.95 \pm .02$ & -2.0 & .35 & $-.46 ; \pm .45$ \\
\hline & $15 \mathrm{~m}$ & $2.34 \pm .07$ & $2.29 \pm .06$ & -1.9 & .17 & $-.63 ; \pm .73$ \\
\hline \multirow{6}{*}{ LMs } & & non-Reserve Team & Reserve Team & & & \\
\hline & $5 m$ & $.97 \pm .04$ & $.97 \pm .03$ & .2 & .93 & $.05 ; \pm .59$ \\
\hline & $15 \mathrm{~m}$ & $2.32 \pm .07$ & $2.31 \pm .04$ & -.5 & .64 & $-.16 ; \pm .49$ \\
\hline & & non-Professional FL & Professional FL & & & \\
\hline & $5 m$ & $.97 \pm .04$ & $.96 \pm .02$ & -.4 & .81 & $-.12 ; \pm .70$ \\
\hline & $15 \mathrm{~m}$ & $2.32 \pm .06$ & $2.30 \pm .03$ & -1.0 & .55 & $-.34 ; \pm .54$ \\
\hline \multirow{6}{*}{ CMs } & & non-Reserve Team & Reserve Team & & & \\
\hline & $5 m$ & $.98 \pm .03$ & $.99 \pm .04$ & .5 & .75 & $.17 ; \pm .80$ \\
\hline & $15 \mathrm{~m}$ & $2.36 \pm .05$ & $2.35 \pm .05$ & -.3 & .67 & $-.16 ; \pm .68$ \\
\hline & & non-Professional FL & Professional FL & & & \\
\hline & $5 m$ & $.99 \pm .03$ & $.96 \pm .03$ & -2.4 & .17 & $-.69 ; \pm 1.01$ \\
\hline & $15 \mathrm{~m}$ & $2.36 \pm .05$ & $2.33 \pm .05$ & -1.0 & .32 & $-.51 ; \pm 1.34$ \\
\hline \multirow{6}{*}{ Fs } & & non-Reserve Team & Reserve Team & & & \\
\hline & $5 m$ & $.98 \pm .04$ & $.95 \pm .02$ & -2.4 & .03 & $-.64 ; \pm .46$ \\
\hline & $15 \mathrm{~m}$ & $2.32 \pm .06$ & $2.28 \pm .04$ & -1.5 & .08 & $-.53 ; \pm .46$ \\
\hline & & non-Professional FL & Professional FL & & & \\
\hline & $5 m$ & $.97 \pm .04$ & $.96 \pm .02$ & -.9 & .53 & $-.26 ; \pm .55$ \\
\hline & $15 \mathrm{~m}$ & $2.30 \pm .06$ & $2.29 \pm .05$ & -.3 & .66 & $-.13 ; \pm .66$ \\
\hline
\end{tabular}

Note. Non-Reserve Team: goalkeepers (Gs) $(n=10)$; lateral defenders (LDs) $(n=20)$; central defenders (CDs) $(n=22)$; lateral midfielders $(L M s)(n=20)$; central midfielders $(C M s)(n=15)$; forwards (Fs) $(n=20)$. Reserve Team: goalkeepers $(G s)(n=3)$; lateral defenders (LDs) $(n=10)$; central defenders (CDs) $(n=8)$; lateral midfielders $(L M s)(n=8)$; central midfielders $(C M s)(n=11)$; forwards $(F s)(n=13)$. Non-Professional FL: goalkeepers $(G s)(n=10)$; lateral defenders $(L D s)(n=25)$; central defenders $(C D s)(n=24)$; lateral midfielders (LMs) $(n=25)$; central midfielders $(C M s)(n=22)$; forwards $(F s)(n=27)$. Professional FL: goalkeepers $(G s)(n$ $=3)$; lateral defenders $(\operatorname{LDs})(n=5)$; central defenders $(C D s)(n=6)$; lateral midfielders $(L M s)(n=3)$; central midfielders $(C M s)(n=$ 4); forwards (Fs) $(n=6)$. 
Table 2. Differences in jump performance $(\mathrm{cm})$ between those who were not promoted to the Reserve Team non-Reserve Team) and those who were (Reserve Team players), and between those who were not promoted to the first or second division (non-Professional FL players) and those who were (Professional FL players), by playing positions

\begin{tabular}{|c|c|c|c|c|c|c|}
\hline & & & & Difference in means (\%) & $\mathrm{p}$ & Effect size \\
\hline \multirow{6}{*}{ Gs } & & non-Reserve Team & Reserve Team & & & \\
\hline & CMJ & $45.6 \pm 4.3$ & $40.5 \pm 3.8$ & -11.1 & .09 & $-1.08 ; \pm 1.30$ \\
\hline & CMJA & $53.6 \pm 3.6$ & $46.6 \pm 5.2$ & -13.3 & $.02^{*}$ & $1.79 ; \pm 2.41$ \\
\hline & & non-Professional FL & Professional FL & & & \\
\hline & CMJ & $45.6 \pm 4.3$ & $40.5 \pm 3.8$ & -11.1 & .09 & $-1.08 ; \pm 1.30$ \\
\hline & CMJA & $53.6 \pm 3.6$ & $46.6 \pm 5.2$ & -13.3 & $.02^{*}$ & $1.79 ; \pm 2.41$ \\
\hline \multirow{6}{*}{ LDs } & & non-Reserve Team & Reserve Team & \multirow{3}{*}{$\begin{array}{l}5.9 \\
8.1\end{array}$} & & \\
\hline & CMJ & $44.7 \pm 3.8$ & $47.4 \pm 4.6$ & & .10 & $.68 ; \pm .74$ \\
\hline & CMJA & $51.6 \pm 4.1$ & $55.8 \pm 4.8$ & & $.02^{*}$ & $.99 ; \pm .72$ \\
\hline & & non-Professional FL & Professional FL & & & \\
\hline & $\mathrm{CMJ}$ & $45.5 \pm 4.2$ & $45.7 \pm 4.8$ & .3 & .95 & $.03 ; \pm 1.07$ \\
\hline & CMJA & $52.6 \pm 4.6$ & $54.8 \pm 5.0$ & 4.1 & .36 & $.45 ; \pm 1.02$ \\
\hline \multirow{6}{*}{ CDs } & & non-Reserve Team & Reserve Team & & & \\
\hline & $\mathrm{CMJ}$ & $43.5 \pm 4.4$ & $45.3 \pm 3.4$ & 4.5 & .29 & $.41 ; \pm .59$ \\
\hline & CMJA & $50.5 \pm 4.2$ & $53.3 \pm 4.2$ & 5.7 & .12 & $.64 ; \pm .71$ \\
\hline & & non-Professional FL & Professional FL & & & \\
\hline & $\mathrm{CMJ}$ & $43.4 \pm 4.2$ & $46.2 \pm 3.4$ & 6.7 & .14 & $.65 ; \pm .68$ \\
\hline & CMJA & $50.6 \pm 4.2$ & $53.5 \pm 4.7$ & 5.7 & .15 & $.67 ; \pm .92$ \\
\hline \multirow{6}{*}{ LMs } & & non-Reserve Team & Reserve Team & & & \\
\hline & CMJ & $45.3 \pm 4.0$ & $43.5 \pm 3.6$ & -3.9 & .26 & $-.43 ; \pm .62$ \\
\hline & CMJA & $53.0 \pm 5.1$ & $50.6 \pm 3.6$ & -4.3 & .21 & $-.45 ; \pm .53$ \\
\hline & & non-Professional FL & Professional FL & & & \\
\hline & CMJ & $44.8 \pm 4.0$ & $44.3 \pm 3.7$ & -1.0 & .83 & $-.13 ; \pm 1.62$ \\
\hline & CMJA & $52.4 \pm 5.0$ & $50.9 \pm 2.1$ & -2.1 & .63 & $-.28 ; \pm .61$ \\
\hline \multirow{6}{*}{ CMs } & & non-Reserve Team & Reserve Team & & & \\
\hline & $\mathrm{CMJ}$ & $42.5 \pm 3.8$ & $42.4 \pm 2.5$ & .1 & .98 & $-.01 ; \pm .53$ \\
\hline & CMJA & $49.2 \pm 5.3$ & $49.8 \pm 3.6$ & 1.6 & .74 & $.12 ; \pm .54$ \\
\hline & & non-Professional FL & Professional FL & & & \\
\hline & CMJ & $42.5 \pm 3.4$ & $42.4 \pm 2.9$ & -.5 & .89 & $-.08 ; \pm 1.50$ \\
\hline & CMJA & $49.1 \pm 4.8$ & $52.1 \pm 1.8$ & 6.5 & .31 & $.59 ; \pm .55$ \\
\hline \multirow{6}{*}{ Fs } & & non-Reserve Team & Reserve Team & & & \\
\hline & CMJ & $44.1 \pm 4.4$ & $45.9 \pm 5.9$ & 3.7 & .34 & $.38 ; \pm .72$ \\
\hline & CMJA & $50.3 \pm 3.8$ & $53.3 \pm 6.3$ & 5.6 & .10 & $.75 ; \pm .85$ \\
\hline & & non-Professional FL & Professional FL & & & \\
\hline & CMJ & $45.1 \pm 5.2$ & $43.7 \pm 4.2$ & -2.8 & .56 & $-.25 ; \pm .70$ \\
\hline & CMJA & $51.5 \pm 5.4$ & $51.5 \pm 3.9$ & .3 & .98 & $.01 ; \pm .63$ \\
\hline
\end{tabular}

Note. Non-Reserve Team: goalkeepers (Gs) $(n=10)$; lateral defenders (LDs) $(n=20)$; central defenders $(C D s)(n=22)$; lateral midfielders (LMs) $(n=20)$; central midfielders (CMs) $(n=15)$; forwards (Fs) $(n=20)$. Reserve Team: goalkeepers $(G s)(n=3)$; lateral defenders (LDs) $(n=10)$; central defenders (CDs) $(n=8)$; lateral midfielders (LMs) $(n=8)$; central midfielders $(C M s)(n=11)$; forwards (Fs) $(n=13)$. Non-Professional FL: goalkeepers $(G s)(n=10)$; lateral defenders (LDs) $(n=25)$; central defenders $(C D s)(n=24)$; lateral midfielders (LMs) $(n=25)$; central midfielders $(C M s)(n=22)$; forwards (Fs) $(n=27)$. Professional FL: goalkeepers $(G s)(n$ $=3)$; lateral defenders (LDs) $(n=5)$; central defenders (CDs) $(n=6)$; lateral midfielders $(L M s)(n=3)$; central midfielders $(C M s)(n=$ 4); forwards (Fs) $(n=6)$.

${ }^{*} p<.05$, significant differences. 
Table 3. Differences in aerobic fitness performance $\left(M A S, \mathrm{~km} \cdot \mathrm{h}^{-1}\right)$ between those who were not promoted to the Reserve Team (non-Reserve Team) and those who were (Reserve Team players), and between those who were not promoted to the first or second division (non-Professional FL players) and those who were (Professional FL players), by playing positions

\begin{tabular}{|c|c|c|c|c|c|}
\hline & & & Difference in means (\%) & $\mathrm{p}$ & Effect size \\
\hline \multirow{4}{*}{ LDs } & non-Reserve Team & Reserve Team & & & \\
\hline & $16.6 \pm .6$ & $16.7 \pm .7$ & .9 & .53 & $.24 ; \pm .69$ \\
\hline & non-Professional FL & Professional FL & & & \\
\hline & $16.6 \pm .7$ & $17.0 \pm .3$ & 2.7 & .17 & $.64 ; \pm .54$ \\
\hline \multirow{4}{*}{ CDs } & non-Reserve Team & Reserve Team & & & \\
\hline & $16.7 \pm .7$ & $16.5 \pm .4$ & -1.2 & .42 & $-.29 ; \pm .47$ \\
\hline & non-Professional FL & Professional FL & & & \\
\hline & $16.7 \pm .7$ & $16.4 \pm .3$ & -2.0 & .23 & $-.50 ; \pm .45$ \\
\hline \multirow{4}{*}{ LMs } & non-Reserve Team & Reserve Team & & & \\
\hline & $16.7 \pm .6$ & $17.2 \pm .5$ & 3.0 & .04 & $.79 ; \pm .60$ \\
\hline & non-Professional FL & Professional FL & & & \\
\hline & $16.9 \pm .6$ & $17.2 \pm .5$ & 2.0 & .38 & $.52 ; \pm 1.35$ \\
\hline \multirow{4}{*}{ CMs } & non-Reserve Team & Reserve Team & & & \\
\hline & $16.5 \pm .5$ & $17.0 \pm .8$ & 2.9 & .06 & $.96 ; \pm .92$ \\
\hline & non-Professional FL & Professional FL & & & \\
\hline & $16.7 \pm .6$ & $17.1 \pm .8$ & 2.6 & .22 & $.70 ; \pm 1.58$ \\
\hline \multirow{4}{*}{ Fs } & non-Reserve Team & Reserve Team & & & \\
\hline & $16.4 \pm .8$ & $16.3 \pm .6$ & -1.0 & .52 & $-.20 ; \pm .50$ \\
\hline & non-Professional FL & Professional FL & & & \\
\hline & $16.4 \pm .8$ & $16.4 \pm .4$ & .5 & .83 & $.09 ; \pm .49$ \\
\hline
\end{tabular}

Note. Non-Reserve Team: lateral defenders (LDs) $(n=20)$; central defenders (CDs) $(n=22)$; lateral midfielders (LMs) $(n=20)$; central midfielders $(C M s)(n=15)$; forwards $(F s)(n=20)$. Reserve Team: lateral defenders (LDs) $(n=10)$; central defenders $(C D s)(n=8)$; lateral midfielders (LMs) $(n=8)$; central midfielders $(C M s)(n=11)$; forwards $(F s)(n=13)$. Non-Professional FL: lateral defenders (LDs) $(n=25)$; central defenders (CDs) $(n=24)$; Lateral Midfielders $(L M s)(n=25)$; central midfielders $(C M s)(n=22)$; forwards $(F s)$ $(n=27)$. Professional FL: lateral defenders $(L D s)(n=5)$; central defenders (CDs) $(n=6)$; lateral midfielders $(L M s)(n=3)$; central midfielders (CMs) $(n=4)$; forwards $(F s)(n=6)$.

${ }^{*} p<.05$, significant differences.

No significant differences $(\mathrm{p}>$.05) were found between the Reserve Team and non-Reserve Team or between the PFL and NPFL players in aerobic fitness for any of the playing positions, except for the lateral midfielders. Specifically, aerobic fitness was greater $(\mathrm{p}<.05 ; \mathrm{ES}=.79 \pm .60$, moderate $)$ in the Reserve Team lateral midfielders in comparison with that for the non-Reserve Team (Table 3).

\section{Discussion and conclusions}

The purpose of this study was to investigate the alleged impact of physical fitness performance (i.e. $5 \mathrm{~m}$ and $15 \mathrm{~m}, \mathrm{CMJ}$, CMJA, MAS) of elite junior soccer players on their professional career according to playing positions. The main findings were as follows: a) $34 \%$ and $12 \%$ of all junior players were promoted to the reserve team and to the $1^{\text {st }}$ Division, respectively; b) overall, the elite junior players who were promoted to the reserve team of the club and to a high-level soccer did not perform better on neuromuscular tests than the other players; and c) aerobic fitness of the promoted lateral midfielders was greater compared with that of the rest of the lateral midfielders. The results suggest that the impact of physical fitness on the promotion of elite junior soccer players is limited.

\section{Promotion success}

Out of all the players enrolled in the junior team of this Spanish $1^{\text {st }}$ Division elite soccer academy in the $1998-2010$ period $16 \%$ were promoted to the $1^{\text {st }}$ or $2^{\text {nd }}$ Spanish Divisions in later years. In the same elite soccer academy, three out of ten players enrolled in the reserve team in the 1994-2012 period competed in the Spanish high level soccer (Castillo, et al., 2018). This suggests that success in the promotion to a high-level soccer is considerably limited in junior soccer players. As talent identification is a long process, the earlier the decision is made the greater the uncertainty about the outcome 
(Gonçalves, et al., 2012). By tactical positions, the percentage of promotions to the $1^{\text {st }}$ or $2^{\text {nd }}$ Spanish Divisions ranged from $11 \%$ (goalkeepers and lateral midfielders) to $25 \%$ (central defenders), while for the players promoted from the reserve team to the Spanish high-level soccer the percentage ranged from $28 \%$ (lateral midfielders) to $38 \%$ (lateral defenders) (Castillo, et al., 2018). It appears that promotion success in each playing position is determined by a competitive level.

\section{Promotion and physical fitness performance}

No significant differences were found ( $p>05)$ in neuromuscular performance (i.e., sprinting and jumping) between the Reserve Team and nonReserve Team or between the PFL and NPFL players in any playing positions, except for three out of the 48 comparisons and for three different playing positions (Tables 1 and 2). In the same line, sprint (i.e., $5 \mathrm{~m}$ and $15 \mathrm{~m}$ times) and jump performances (i.e., CMJ) were not a relevant physical parameter to promotion of players from an elite reserve team to the top level of soccer in Spain, except for central defenders (Martinez-Santos, et al., 2016). This suggested that, after a continuous selection process in the elite soccer academies (Bidaurrazaga-Letona, Lekue, Amado, \& Gil, 2019), neuromuscular performance did not determine the promotion of junior and reserve team young soccer players to a high-level soccer for most of the playing positions (Martinez-Santos, et al., 2016). It seems that other performance factors (e.g., players' tactical and emotional dimensions) determine the selection of young soccer players (i.e., junior and reserve players) for competing at a high level (Dodd \& Newans, 2018). While a higher profile in sprinting and jumping (i.e., $5 \mathrm{~m}, 15 \mathrm{~m}$ and $\mathrm{CMJ}$ ) has shown to be an advantage for the promotion of the reserve team central defenders to a high-level soccer (Martinez-Santos, et al., 2016), no significant differences were found between the Reserve Team and non-Reserve Team or between the PFL and NPFL central defenders, suggesting that neuromuscular performance can be an advantage in the last step to a high-level soccer for central defenders.

Significant differences were not found $(p>.05)$ in aerobic fitness performance between the Reserve Team and non-Reserve Team or between the PFL and NPFL players in any playing positions, except in lateral midfielders. In the same line, Castillo et al. (2018) did not find differences ( $p>.05)$ between the players promoted to the Spanish PFL (i.e., $1^{\text {st }}$ and $2^{\text {nd }}$ Divisions) and those not promoted by playing positions (i.e., goalkeepers, lateral defenders, central defenders, lateral midfielders, central midfielders, and forwards). This suggests that once young players of an elite soccer academy are promoted to the junior team of the club their aerobic fitness performance did not determine their promotion to a highlevel soccer (Dodd \& Newans, 2018). Performance in aerobic fitness was only significantly $(\mathrm{ES}=.79 \pm$ .60 ; moderate) greater for the Reserve Team lateral midfielders compared to that for the non-Reserve Team lateral midfielders (Table 3), suggesting that a higher MAS performance could be an advantage for these players, but not for the rest of the playing positions, in their promotion from the junior to the reserve team in an elite soccer academy. Castillo et al. (2018) found that aerobic endurance performance did not determine the promotion from an elite reserve team to the Spanish PFL for lateral midfielders. It seems that the aerobic component is a relevant physical fitness parameter for lateral midfielders only until being promoted to the reserve team, but it does not determine their promotion to the PFL level. Better physical fitness means covering greater total distances, running longer distances at a high-intensity level and performing more high-speed bouts than other tactical positions (Bradley, et al., 2009; Bush, Barnes, Archer, Hogg, \& Bradley, 2015; Carling, 2013; Di Salvo, et al., 2010; Lago, Casais, Dominguez, \& Sampaio, 2010; Palucci Vieira, Carling, Barbieri, Aquino, \& Pereira Santiago, 2019; Vigne, Gaudino, Rogowski, Alloatti, \& Hautier, 2010).

The results suggest that, overall, the impact of neuromuscular performance (i.e., sprinting and jumping) and aerobic fitness on the promotion of elite junior soccer players is limited. Despite other physical fitness tests not being used to evaluate physical fitness performance of the players and assess their impact on the promotion to a high-level soccer and the characteristics of the club can determine the success of the players, several considerations can be taken into account at a practical level. The reference values of jumping and sprinting performances and aerobic fitness in junior professional soccer players, obtained in this study, can be used by sport technicians in soccer schools to assess the physical fitness performance level of their players. Since it seems that, in general, players belonging to an elite junior team show an appropriate physical fitness performance profiles, coaches can pay greater attention to other dimensions of the players (e.g., tactical dimension). 


\section{References}

Altmann, S., Ringhof, S., Neumann, R., Woll, A., \& Rumpf, M.C. (2019). Validity and reliability of speed tests used in soccer: A systematic review. PloS One, 14(8), e0220982.

Bidaurrazaga-Letona, I., Lekue, J.A., Amado, M., \& Gil, S.M. (2019). Progression in youth soccer: Selection and identification in youth soccer players aged 13-15 years. Journal of Strength and Conditioning Research, 33(9), 2548-2558.

Bradley, P.S., Sheldon, W., Wooster, B., Olsen, P., Boanas, P., \& Krustrup, P. (2009). High-intensity running in English FA Premier League soccer matches. Journal of Sports Sciences, 27(2), 159-168.

Bush, M., Barnes, C., Archer, D.T., Hogg, B., \& Bradley, P.S. (2015). Evolution of match performance parameters for various playing positions in the English Premier League. Human Movement Science, 39, 1-11.

Carling, C. (2013). Interpreting physical performance in professional soccer match-play: Should we be more pragmatic in our approach? Sports Medicine, 43(8), 655-663.

Carling, C., Le Gall, F., \& Malina, R.M. (2012). Body size, skeletal maturity, and functional characteristics of elite academy soccer players on entry between 1992 and 2003. Journal of Sports Sciences, 30(15), 1683-1693.

Castillo, D., Los Arcos, A., \& Martínez-Santos, R. (2018). Aerobic endurance performance does not determine the professional career of elite youth soccer players. Journal of Sports Medicine and Physical Fitness, 58(4), $392-398$.

Castillo, D., Pérez-González, B., Raya-González, J., Fernández-Luna, Á., Burillo, P., \& Lago-Rodríguez, Á. (2019). Selection and promotion processes are not associated by the relative age effect in an elite Spanish soccer academy. PloS One, 14(7), 0219945.

Coelho E Silva, M.J., Figueiredo, A.J., Simões, F., Seabra, A., Natal, A., Vaeyens, R., Philippaerts, R., Cumming, S.P., \& Malina, R.M. (2010). Discrimination of U-14 soccer players by level and position. International Journal of Sports Medicine, 31(11), 790-796.

Cohen, J. (1988). Statistical power analysis for the behavioral sciences (2nd ed.). L. Erlbaum Associates.

Craig, T.P., \& Swinton, P. (2020). Anthropometric and physical performance profiling does not predict professional contracts awarded in an elite Scottish soccer academy over a 10-year period. European Journal of Sport Science, doi: 10.1080/17461391.2020.1808079

Di Salvo, V., Baron, R., González-Haro, C., Gormasz, C., Pigozzi, F., \& Bachl, N. (2010). Sprinting analysis of elite soccer players during European Champions League and UEFA Cup matches. Journal of Sports Sciences, 28(14), 1489-1494.

Dodd, K.D., \& Newans, T.J. (2018). Talent identification for soccer: Physiological aspects. Journal of Science and Medicine in Sport, 21(10), 1073-1078.

Gil, S.M., Zabala-Lili, J., Bidaurrazaga-Letona, I., Aduna, B., Lekue, J.A., Santos-Concejero, J., \& Granados, C. (2014). Talent identification and selection process of outfield players and goalkeepers in a professional soccer club. Journal of Sports Sciences, 32(20), 1931-1939.

Gonaus, C., Birklbauer, J., Lindinger, S.J., Stöggl, T.L., \& Müller, E. (2019). Changes over a decade in anthropometry and fitness of elite Austrian youth soccer players. Frontiers in Physiology, 10, 333.

Gonçalves, C.E.B., Rama, L.M.L., \& Figueiredo, A.B. (2012). Talent identification and specialization in sport: An overview of some unanswered questions. International Journal of Sports Physiology and Performance, 7(4), 390-393.

Hopkins, W. (2007). A spreadsheet for deriving a confidence interval, mechanistic inference and clinical inference from a p value. Sportscience, 11, 16-20.

Hopkins, W.G., Marshall, S.W., Batterham, A.M., \& Hanin, J. (2009). Progressive statistics for studies in sports medicine and exercise science. Medicine and Science in Sports and Exercise, 41(1), 3-13.

Huijgen, B.C.H., Elferink-Gemser, M.T., Lemmink, K.A.P.M., \& Visscher, C. (2014). Multidimensional performance characteristics in selected and deselected talented soccer players. European Journal of Sport Science, 14(1), 2-10.

Kuipers, H., Verstappen, F.T., Keizer, H.A., Geurten, P., \& van Kranenburg, G. (1985). Variability of aerobic performance in the laboratory and its physiologic correlates. International Journal of Sports Medicine, 6(4), 197-201.

Lago, C., Casais, L., Dominguez, E., \& Sampaio, J. (2010). The effects of situational variables on distance covered at various speeds in elite soccer. European Journal of Sport Science, 10(2), 103-109.

Lago-Peñas, C., Rey, E., Casáis, L., \& Gómez-López, M. (2014). Relationship between performance characteristics and the selection process in youth soccer players. Journal of Human Kinetics, 40, 189-199.

le Gall, F., Carling, C., Williams, M., \& Reilly, T. (2010). Anthropometric and fitness characteristics of international, professional and amateur male graduate soccer players from an elite youth academy. Journal of Science and Medicine in Sport / Sports Medicine Australia, 13(1), 90-95.

Léger, L., \& Boucher, R. (1980). An indirect continuous running multistage field test: The Université de Montréal track test. Canadian Journal of Applied Sport Sciences=Journal Canadien des Sciences Appliquées au Sport, 5(2), 77-84.

Los Arcos, A., Martínez-Santos, R., \& Castillo, D. (2020). Spanish elite soccer reserve team configuration and the impact of physical fitness performance. Journal of Human Kinetics, 31(71), 211-218. 
Los Arcos, A., \& Martins, J. (2018). Physical fitness performance of young professional soccer players does not change during several training seasons in a Spanish elite reserve team: A club study, 1996-2013. Journal of Strength and Conditioning Research, 32(9), 2577-2583.

Los Arcos, A., Mendiguchia, J., \& Yanci, J. (2017). Specificity of jumping, acceleration and quick change of direction motor abilities in soccer players. Kinesiology, 49(1), 22-29.

Los Arcos, A., Vázquez, J.S., Villagra, F., Martín, J., Lerga, J., Sánchez, F., Bertó, J., \& Zulueta, J.J. (2019). Assessment of the maximal aerobic speed in young elite soccer players: Université de Montréal track test (UM-TT) vs treadmill test. Science and Sports, 34, 267-271.

Martinez-Santos, R., Castillo, D., \& Los Arcos, A. (2016). Sprint and jump performances do not determine the promotion to professional elite soccer in Spain, 1994-2012. Journal of Sports Sciences, 34(24), 2279-2285.

Mills, A., Butt, J., Maynard, I., \& Harwood, C. (2012). Identifying factors perceived to influence the development of elite youth football academy players. Journal of Sports Sciences, 30(15), 1593-1604.

Palucci Vieira, L.H., Carling, C., Barbieri, F.A., Aquino, R., \& Pereira Santiago, P.R. (2019). Match running performance in young soccer players: A systematic review. Sports Medicine, 49(2), 289-318.

Reilly, T., Williams, A.M., Nevill, A., \& Franks, A. (2000). A multidisciplinary approach to talent identification in soccer. Journal of Sports Sciences, 18(9), 695-702.

Roca, A., Williams, A.M., \& Ford, P.R. (2012). Developmental activities and the acquisition of superior anticipation and decision making in soccer players. Journal of Sports Sciences, 30(15), 1643-1652.

Rodríguez-Rosell, D., Mora-Custodio, R., Franco-Márquez, F., Yañez-García, J.M., \& González-Badillo, J.J. (2017). Traditional vs. sport-specific vertical jump tests: Reliability, validity, and relationship with the legs strength and sprint performance in adult and teen soccer and basketball players. Journal of Strength and Conditioning Research, 31(1), 196-206.

Vaeyens, R., Coutts, A., \& Philippaerts, R.M. (2005). Evaluation of the «under-21 rule»: Do young adult soccer players benefit? Journal of Sports Sciences, 23(10), 1003-1012.

Vaeyens, R., Lenoir, M., Williams, A.M., \& Philippaerts, R.M. (2007). Mechanisms underpinning successful decision making in skilled youth soccer players: An analysis of visual search behaviors. Journal of Motor Behavior, 39(5), 395-408.

Vega, J.M., Gonzalez-Artetxe, A., Aguinaco, J.A., \& Los Arcos, A. (2020). Assessing the anthropometric profile of Spanish elite reserve soccer players by playing position over a decade. International Journal of Environmental Research and Public Health, 17(15), 5446.

Vigne, G., Gaudino, C., Rogowski, I., Alloatti, G., \& Hautier, C. (2010). Activity profile in elite Italian soccer team. International Journal of Sports Medicine, 31(5), 304-310.

Zuber, C., Zibung, M., \& Conzelmann, A. (2016). Holistic patterns as an instrument for predicting the performance of promising young soccer players-A 3-year longitudinal study. Frontiers in Psychology, 7, 1088.

Submitted: November 20, 2017

Accepted: February 18, 2021

Published Online First: April 12, 2021

Correspondence to:

Asier Los Arcos, Ph.D.

Department of Physical Education and Sport,

University of the Basque Country, UPV/EHU, Vitoria-

Gasteiz, Spain

E-mail: asier.losarcos@ehu.eus

\section{Acknowledgements}

The authors gratefully acknowledge the support of the Spanish government subproject Integration ways between qualitative and quantitative data, multiple case development, and synthesis review as main axis for an innovative future in physical activity and sports research [PGC2018-098742-B-C31] (Ministerio de Ciencia, Innovación y Universidades, Programa Estatal de Generación de Conocimiento y Fortalecimiento Científico y Tecnológico del Sistema I + D + i), that is part of the coordinated project New approach of research in physical activity and sport from mixed methods perspective (NARPAS_MM) [SPGC201800X098742CV0]. 